\title{
Communication Skills during the Pandemic Times
}

\author{
K Chandrasekharan Nair ${ }^{1 *}$, Pradeep Dathan ${ }^{2}$ and Bhimalingesvara \\ $\mathbf{R a o}^{3}$ \\ ${ }^{1}$ Professor Emeritus, Department of Prosthodontics, Sri Sankara Dental College, \\ Akathumuri, Thiruvananthapuram, Kerala, India \\ ${ }^{2}$ Professor and Head of the Department of Prosthodontics, Sri Sankara Dental \\ College, Akathumuri, Thiruvavananthapuram, Kerala, India \\ ${ }^{3}$ Professor of Prosthodontics, Vishnu Dental College, Bhimavaram, Andhra Pradesh, \\ India \\ *Corresponding Author: K Chandrasekharan Nair, Professor Emeritus, Department \\ of Prosthodontics, Sri Sankara Dental College, Akathumuri, Thiruvananthapuram, \\ Kerala, India.
}

Received: August 11, 2021

Published: August 28, 2021

(C) All rights are reserved by

K Chandrasekharan Nair., et al.

\begin{abstract}
Communication skills are essentially to be procured by health professionals along with professional skills. The relevance of communication got enhanced during the pandemic times when patients had limited direct access to the docly describes thetors. The restrictions got compensated by the timely developments that happened in the communication channels. This article briefly describes the basics of communication which are relevant to both medical and dental profession.

Keywords: Communication Skills; Speaking; Listening; Conversation; Webinars
\end{abstract}

\section{Introduction}

Communication is a vital part of our daily routine and is a process by which information is exchanged between individuals through a common system of symbols signs or data. Most of our communication is through speaking. When we speak, someone should listen to it or else communication will not be useful. When patient speaks, the doctor should listen patiently. Then the doctor responds by seeking details of the disease. The patient will continue speaking and the doctor will continue listening. In fact, communication is a cyclic process. Teacher-student relation is also another finest example of communication. Teacher gives information and the students listen to the teacher. When the student has a doubt, he raises the hand and raises his doubt. Teacher clarifies the doubt and the process continues.
When we calculate the time spent on the different routes of communication viz. speaking, listening, reading and writing, scientists have found that the time distribution is in the following order: Listening (45\%), Speaking (30\%), Reading (16\%) and Writing (9\%).

Will the students listen fully to what the teacher tells? Will the patient listen to all the instructions given by the doctor and carry out those instructions meticulously? Sadly, the answer is a big 'No'. Either in a class room or in a doctor's consultancy, only one fourth of what is spoken is listened to. Most of the people selectively enjoy deafness and they claim that related matter was not explained at all. In the class rooms students, day dream and the learning does not happen. It is now universally accepted that dental professionals 
should give equal importance to both professional skills and communication skills.

In a doctor/dentist's professional career, it is estimated that nearly 20000 interviews are conducted. This fact clearly highlights the importance of acquiring the skills of communication. It has been observed that doctors with good communication skills identify patients' problems more precisely. And their patients' satisfaction level is also high. In turn, the doctors also get job satisfaction and they do not feel the job stress much. The doctor who allowed the patients to talk about their family are very popular with the patients.

Patients have a feeling that most of the doctors interrupted them within 20 to 25 seconds and they do not get the satisfaction. The doctors who claim to spend a minimum of 10 minutes with each patient, in reality spends only one minute per patient. Educated patients, though not revealed, have a complaint that they are not involved in the decision-making process about their care. Often, they feel that they are compelled to accept a treatment which the doctor decides. Satisfaction level on the information provided to the patient is also low. Information on when to resume normal activities is seldom given. The drugs prescribed are not explained and most of the patients rely heavily on internet resources. Patients working in IT field are received by the doctors with skepticism. Affordability of the treatment is very seldom considered by the doctors and many such incidents got revealed during the pandemic.

Test results are not explained to the patient and hence patients feel that most of the tests are done without any reason. The pandemic compelled online consultations but the entire system could not claim success because of the limited accessibility. A good doctor patient relation can be nurtured with reasonably good communication.

Though very essential, the process of communication is considered as a tough job. Osmo Antero Wiio, a Finnish academic, journalist, author and member of the Finnish Parliament has formulated certain laws about communication:

- Communication usually fails, except by accident - if a communication is begun with this assumption, the results may be better than starting with the assumption of success. The general efficiency of communication is rated as very low; as low as $5 \%$.
- If a message can be interpreted in several ways, it will be interpreted in a manner that maximizes damages.

- There is always somebody who understands your message better than you.

- The more we communicate, the more difficult for communication to succeed.

\section{Conversation}

Conversing with other people is an art to be developed by health professionals. Many are reluctant to start a conversation mainly because of the fear of rejection. But patients will not behave like that because they have to reveal themselves to get the services. Doctors seek information and collect them during the course of conversation. The conventional body language norms like smile, open posture, forward lean, touch, eye contact and nod may not be successful during the clinical conversation at present because of the protective PPE kits. Only the voice comes to the rescue of the dentist. Precisely designed questionnaire can be a good tool during the pandemic time if it is employed through the reception staff.

\section{Listening}

A large number of professionals think that listening is an essential skill but very few are formally trained to listen. Training facilities for listening are very limited in our country and that too for health care professionals. Training has to be incorporated in the curriculum as a beginning step. Most of the time we think at a faster pace of 1000 to 3000 words per minute. And our listening capacity is only 125 to 250 words per minute. That is the reason we get distracted easily. Moreover, we can remember only $20 \%$ of what we hear. An active effort is required to remember the facts told in the class.

\section{How to improve listening}

In discussions, the best rule to be followed is that 'not to interrupt the speaker' and at the same time no one should be allowed to monopolise also. Some organisations have implemented the policy of NOSTUESO. This is an acronym that stands for "No One Speaks Twice Until Everybody Speaks Once”.

This rule in a discussion compels everyone to listen.

In conversations, we have to be very careful especially while giving or receiving instructions. If a patient opts for week end ap- 
pointments usually, the staff in the dental clinic assumes that the patient prefers week end appointments. On the contrary now the patient prefers mid-week appointments. So, every time an appointment is given, the preference has to be rechecked and that is a safer option. The Post extraction instructions should be repeated every time the patient undergoes a dental extraction.

A speaker's dress, accent and age may force the listener to make some judgements on the speaker and that may hinder listening. We should not let our opinions on a speaker to prevent us from listening carefully to what is being said.

Good listeners have the ability to empathize with the speaker especially in the doctor patient relationship. They observe closely and try to read the speaker (patients)'s body language. Perhaps the speaker's pained expression or sign of tension may indicate that he or she is nervous. A halting style of speech or emotional tone of voice may also indicate that the individual is upset. Only 7 percent of our message comes through the words, 38 percent comes through the tone of voice, and 55 percent comes through the body language.

To stay focused during long presentations, it is better to take notes containing the main ideas. This will help the student to concentrate and avoid becoming distracted. Some presentations are followed by question-and-answer sessions. It's often a good idea to formulate questions while you are listening to the speaker. This is another way to concentrate on what he or she is saying, avoid boredom and focus attention on the main ideas. Good questions will provide you with additional information.

John Marshall, the fourth Chief Justice of the Supreme Court of the United States (1801-1835) stated that "To listen well is as powerful a means of communication and influence as to talk well." Even today this statement stands relevant in the field of communication.

\section{Speaking in webinars}

In the initial stages of the pandemic, educational process in the country was stalled. Schools and colleges were closed. Parents, students and teachers were in a state of panic. Slowly everyone has reconciled with the reality. Students and teachers have become experts in the online mode. From nursery classes to professional colleges, students and teachers got adapted to the online teaching and learning systems. Zoom has become a household word. Most of the teachers have become experts in conducting classes online and webinars have become so common that now parents doubt whether we will ever go back to our old system. Webinars are conducted in professional colleges and some guidelines are described here.

\section{Learn the technology}

Irrespective of the age and expertise, teachers and students have to master the nuances of the online platforms. Spend time in learning how to interact with the software and concentrate all your efforts on a decent delivery.

\section{Avoid reading script}

In webinars a speaking style is always preferred rather than reading a script. So that audience will feel that the speaker is addressing them directly. The content of the lecture should be clearly stated in the beginning. The class should adhere to a strict time frame otherwise participants may drop off towards the end.

\section{Speak with authority}

The speaker should speak with authority. Towards the end of each sentence the volume should not get reduced so that audibility is ensured. Make sure that a good quality mike is used. When a doubt is raised, answer in clear cut terms. Audience should be able to feel the clarity and authoritativeness on the subject.

\section{Be comfortable}

To focus on the speech, the speaker should not get distracted. The speaker should be comfortable in dress and sitting to minimise distraction. Drinking water should be kept nearby so that it will become handy when an unexpected urge to cough come due to dryness of the mouth or scratchy throat.

\section{Smile}

Keep smiling during the webinar so that it will encourage the listeners to be present during the seminar. In fact, smiling is contagious and webinar becomes a pleasant experience.

\section{Record and correct irregular speech habits}

Rehearse and record your speech so that common speech quirks like "umm" and "annnd" can be avoided and it will portray that you are articulate and well spoken.

\section{Be passionate}

The audience should feel that you are passionate, emotional and believing in your content. Speaking on emotive and passionate top- 
ics will naturally vary your intonation. When you are passionate about your topic, it is much easier for the audience to be captivated and fully engaged.

\section{Sit straight}

Sitting or standing straight will improve breathing, thereby improving your voice. The benefits of taking deep breaths are numerous, and will only improve the public speaking ability. Taking deep breaths release tension, allowing you to relax.

\section{Writing}

Writing is a powerful tool of communication, used from time immemorial. Dental professional should master the art of writing to establish himself in the scientific world through papers and books. Before writing anything it is better to go through the words of Aristotle, the Greek philosopher: "To write well, express yourself like common people, but think like a wise man".

Writing should have purpose and that should be stated in the beginning with minimum number of words. Reading unclear long sentences cannot attract and sustain the attention of the reader. Mistakes in grammar, punctuation and spelling must be avoided so that the meaning of what you write will be understood precisely by the reader who belongs to any country of the world. Characteristics of good writing are: compelling, concise, clear and correct. If your writing has clear focus, you must be able to summarise it in two or three sentences. Good writing is always a product of intense proof reading. Never do the proof reading immediately after completing the project and that too on the computer screen. After a day or two, do the proof reading, three times: once for content, clarity, and conciseness, once for grammar and punctuation and once to make sure you've used the right words.

In fact, dental students are progressively lacking the writing skill especially coherent sentences with meaning. Answer books received in exams stand testimony to this fact. Now the answer books are completely filled up with bullet points even for an 'one hour' long essay. The MCQ pattern of testing has brought in this handicap. May be this is the reason why our young professionals do not find it comfortable to write good papers and get them published.

Interpersonal skills become so natural that we often take them for granted, never thinking about how we communicate with other people. The foundation for many other skills, however, are built on strong interpersonal skills, since these are relevant to our personal relationships, social affairs and professional lives.

\section{Non verbal communication}

Verbal communication is related to what a person says. Nonverbal communication includes gestures, facial expression, eye contact, body language and clothes. Paralinguistics relates to how they say it and includes voice tone and volume, speed of speech and the 'uhms' and 'ahs' they say. Research on the subject shows that value judgments on an individual are based on three factors: Verbal (7\%), Paralinguistics (38\%), Non-verbal (55\%).

While the patient is speaking, the doctor should make an effort to convince the patient that he is actively listening. Along with appropriate verbal responses, paralinguistics and nonverbal communication components are required. The acronym SOLER is useful for the non-verbal demonstration of listening: Sit Squarely, Open posture, Leaning forward, Making Eye contact and remain Relaxed (Figure 1).
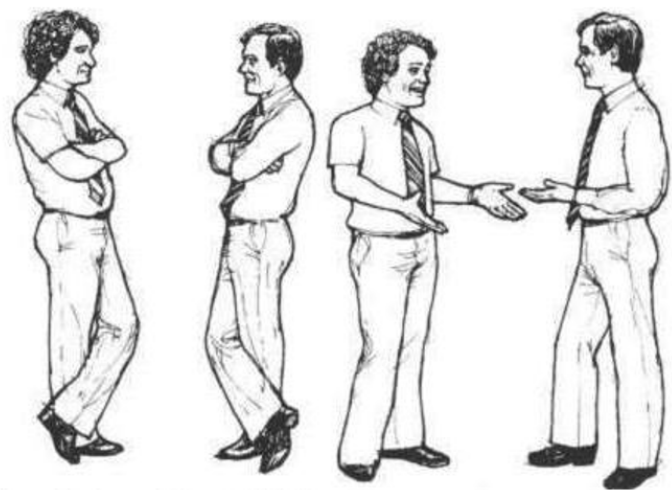

Figure 1: Closed and open posture.

\section{Communication barriers}

In general communication barriers include cultural and religious beliefs, socio economic status and family values. Communication related to dental health may not be successful always due to a number of reasons viz. a bad past experience of dental treatment, fear of getting criticized by the dental health professional about his 
oral health status, patient's thinking that the advices of the dentist are too frivolous, inability to comply with the instructions, financial constraints to undergo the treatment process and the reluctance to change the life style especially on food habits.

Physical appearance, facial expression, gestures and positive and negative nonverbal behavior are factors that are to be considered in conventional nonverbal communication but in the days of the pandemic the communication is greatly affected because of the personal protection equipment. Speaking and writing have to be developed to compensate the limitations in non verbal communication experienced during the pandemic (Figure 2) [1-5].

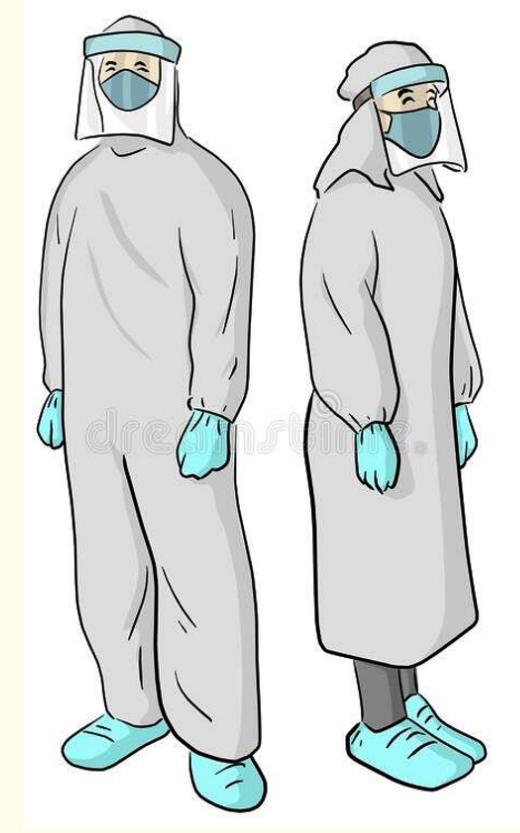

Figure 2: PPE kit masks the expressions and gestures.

\section{Conclusion}

Imparting dental health requires effective utilization of communication skills including both verbal and nonverbal routes. All the conventional routes experienced a limitation during the pandemic time. Speaking, listening and nonverbal communication had suffered during the pandemic. Adequate compensation can be made by developing visual communication including writing, reading, showing pictures and demonstrations. Let us all hope for a speedy recovery from the present situation.

\section{Bibliography}

1. Mike Wanless. Can you help your patients through better communication? 23-26.

2. https://info.workcast.com/blog/top-10-tips-for-webinar-presenters

3. http://www.bctrainingsolutions.com/effective-communication/

4. https://speechhowtos.wordpress.com/2014/11/24/bodymovements-posture/

5. https://www.dreamstime.com/illustration/ppe.html

\section{Volume 5 Issue 9 September 2021 \\ (C) All rights are reserved by K Chandrasekharan Nair., et al.}

